\title{
ESTRATEGIAS METODOLÓGICAS PARA LA INTERPRETACIÓN Y EL ANÁLISIS DE LA OBRA LITERARIA EL INGENIOSO HIDALGO DON QUIJOTE DE LA MANCHA
}

\author{
Marlene Aguirre Chaves ${ }^{1}$ \\ Silvia Elena García Vargas ${ }^{2}$
}

\section{Resumen}

Esta propuesta metodológica surge a partir de un estudio investigativo realizado con docentes de secundaria, en el área de español, con el fin de conocer las estrategias metodológicas que se emplean en el espacio del aula para comprender y analizar la obra literaria El Ingenioso Hidalgo Don Quijote de la Mancha.

Los propósitos que se establecieron para la investigación fueron los siguientes:

- Identificar las técnicas y los instrumentos que desarrollan las(os) profesoras(es) de español para estudiar la obra literaria El Ingenioso Hidalgo Don Quijote de la Mancha. - Conocer la metodología que utilizan las(os) profesoras(es) de espa- ñol para desarrollar la obra literaria El Ingenioso Hidalgo Don Quijote de la Mancha.

Proponer una unidad didáctica para desarrollar las inteligencias múltiples en el estudio de la obra literaria El Ingenioso Hidalgo Don Quijote de la Mancha.

A partir del análisis de los datos, se presenta una serie de estrategias metodológicas para la interpretación y el análisis de la novela El Ingenioso Hidalgo Don Quijote de la Mancha, que contribuyen a mejorar el proceso de enseñanza y aprendizaje, en la asignatura de español, en particular, cambiar la percepción negativa que tienen las y los estudiantes sobre la lectura de la obra cumbre de Miguel de Cervantes.

\footnotetext{
${ }^{1}$ Licenciada en Ciencias de la Educación con énfasis en Didáctica del Espan̄ol, Universidad Nacional. Actualmente labora en la División de Educología, CIDE, de la Universidad Nacional.

2 Licenciada en Ciencias de la Educación con énfasis en Didáctica del Español, Universidad Nacional. Actualmente labora en el Colegio Técnico Profesional de Ulloa.
} 
This methodological proposal came up from an investigative study that was done with high school teachers in the subject of Spanish with the objective of knowing the methodological strategies that are used in the classroom space to comprehend and analize the literary work of El Ingenioso Hidalgo Don Quijote de la Mancha.

The objectives that were established were the following:

- To identify the techniques and instruments that the Spanish teachers developed to study the literary work of El Ingenioso Hidalgo Don Quijote de la Mancha.

- $\quad$ To know the methodology that is used by the Spanish teachers to developed the literary work of $\mathrm{El} \mathrm{In}$ -

\section{Mancha.}

- To propose a didactic unit to develop the multiple intelligencies in the literary study of the literary work of El Ingenioso Hidalgo Don Quijote de la Mancha.

After analysing the data, a series of methodological strategies to interpret and analyse the novel El Ingenioso Hidalgo Don Quijote de la Mancha, which contributes to improve the teaching and learning process in the Spanish subject, in particular, to change the negative perception that the students have about reading the masterpiece of Miguel de Cervantes.

\section{Palabras claves}

Lectura literaria, construccionismo, inteligencias múltiples, innovación, metodología.

\section{Justificación}

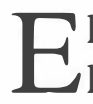

l interés por mejorar la calidad de la educación en nuestro país es una de las políticas más claras que han planteado los más recientes gobiernos. En los últimos años, creció la preocupación por las serias deficiencias que muestran las(os) educadoras(es) en el desarrollo de los contenidos y la evaluación del proceso educativo en la educación secundaria, lo que ha provocado que las y los estudiantes observen la educación como una pérdida de tiempo.

El Ministerio de Educación Pública (MEP) ha realizado múltiples investigaciones que han provocado expectativas y preocupaciones entre los padres de familia, educadoras(es), directoras(es) y estudiantes, porque evidencian que el sistema educativo costarricense necesita urgentemente cambios, los cuales le permitan a la y el joven motivarse $y$, a su vez, que le sean útiles para su desarrollo intelectual, social y laboral. Estas transformaciones podrían eliminar el proceso educativo rígido e inflexible que se ha infiltrado en el sistema educativo actual.

La iniciativa de realizar modificaciones en el sistema educativo, que beneficien a la y al estudiante para mejorar su educación, no ha pasado de ser un 
ideal; al no ser alcanzado, provoca desmotivación y aburrimiento entre las y los jóvenes, porque los programas no responden y no llenan las expectativas.

De acuerdo con lo anterior, cabe preguntarse, ¿cómo mejorar la enseñanza?, ¿será necesario reestructurar los programas de estudio o quizás lo que se necesite es usar nuevas metodologías didácticas en el proceso de enseñanza?, ¿el rendimiento académico es responsabilidad de la y el docente o del ambiente familiar? El análisis y la reflexión no terminan aquí, es necesario recalcar algunos factores negativos que influyen en el desarrollo del proceso de enseñanza y aprendizaje.

Muchas(os) especialistas en educación apuntan que el problema está en la forma de aprender los conocimientos. Vale rescatar que si la o el estudiante es capaz de acomodar y asimilar el conocimiento, logrará desenvolverse sin problemas en el ámbito laboral y en las diversas situaciones que surjan en su vida cotidiana.

Lamentablemente aún nos invade la corriente educativa conocida como "conductismo", que se origina en los años 70 y que hasta ahora ha impedido que la estimulación de la inteligencia de las y los estudiantes aumente. No obstante, no se puede analizar sólo los factores negativos descubiertos cada día en los estudios que se realizan en el campo educativo. También se deben buscar soluciones inmediatas que cambien la percepción de las y los estudiantes hacia la educación costarricense. Lo importante es rescatar el enfoque curricular vigente en la Política Educativa "Hacia el Siglo XXI", porque influye directamente en el trabajo diario desarrollado por las y los docentes en el aula. Este enfoque denominado constructivista, le permite tanto a la o el docente como a la(al) educanda(o), motivar, dinamizar y aumentar el desarrollo intelectual del individuo.

Bien es cierto que existe una serie de problemas en nuestro sistema educativo; por eso, es necesario mejorar la infraestructura, eliminar la sobrepoblación y el sistema memorístico, aumentar las becas, cambiar los métodos y técnicas de enseñanza y abastecer a las instituciones educativas de recursos didácticos.

Estos objetivos son difíciles de lograr, porque se necesita tiempo, dinero, profesionales, en fin, muchos recursos más que el gobierno no puede suministrar. También está en manos de la educadora o el educador el que haya un cambio en el mejoramiento de la enseñanza y es necesario que innove, cambie su metodología e implemente nuevas técnicas de instrucción en los contenidos que desarrolla con sus estudiantes.

Este cambio metodológico le facilitará a la(al) educanda(o) la construcción de su conocimiento y la capacidad de análisis y de criterio que necesita 
para enfrentarse a su entorno. También le permitirá aprender el conocimiento en el aula, utilizando los dos hemisferios que estimulan todos sus sentidos y las inteligencias múltiples.

Por ello, se considera que esta investigación constituye un aporte valioso para las educadoras y los educadores de español que recién inician sus tareas; podría servir de apoyo y ser una guía para facilitar su trabajo en el aula, pues pretende ser una herramienta que ayude a evaluar en forma objetiva y sistemática el trabajo diario.

\section{Consideraciones teóricas}

La Política Educativa "Hacia el Siglo XXI" (1994) define los fines y objetivos de la educación, el tipo de persona y sociedad que se espera formar, los enfoques curriculares, los instrumentos y recursos; en fin, todas las expectativas e intencionalidades que la sociedad le plantea al sistema educativo. Entre estos, son de especial y particular importancia para las y los docentes, los relativos a asuntos curriculares, es decir, que se refieren específicamente al desarrollo de la práctica pedagógica. En estas decisiones curriculares, un elemento indispensable es el enfoque curricular, el cual orientará la práctica educativa y pedagógica.

Desde la perspectiva teórica, hay diferentes planteamientos y algunas(os) autoras(es) incluyen varias clasificaciones de los enfoques curriculares: psicologista, academicista, intelectualista, tecnológico, dialéctico, y constructivista, el cual en la actualidad se constituye como una nueva propuesta de enfoque.

En este último caso, se hará una descripción más detallada por ser el enfoque que se utiliza en este trabajo, en contraposición con el academicista. Es necesario aclarar que casi nunca estos enfoques se presentan en forma pura. Por lo general, se da una posición ecléctica, en la que se toman algunos elementos de cada uno y se complementan con aportes de otro.

El quehacer pedagógico debe ser congruente con el enfoque curricular vigente. En muchos casos, los documentos curriculares orientadores, como la política educativa, los programas y planes de estudio o las guías didácticas dirigidas a las y los docentes, no explican y, entonces, debe hacerse un análisis en torno a como se asumirán los diversos elementos del currículo.

La inclinación por un determinado enfoque curricular es un acuerdo, el cual se asume en el ámbito nacional, la o el docente no tiene participación, se establece la diferencia en su aplicación cuando la educadora o el educador tiene claridad conceptual y práctica para reconocer la opción teórica curricular asumida por el sistema educativo en que trabaja, pues puede variar en un sistema educativo, de acuerdo con lo que se pretende alcanzar. 
Por esta razón, las y los docentes deben conocer las propuestas de los diferentes enfoques, y tomar en cuenta las implicaciones que tiene cada uno de ellos en el momento de realizar el planeamiento didáctico.

\section{Enfoques curriculares}

En este trabajo se seleccionaron dos enfoques: uno, el academicista, enfoque tradicional en el sistemaeducativo; el otro, el constructivista, eje de nuestra investigación, y que se contrapone al primero. La descripción de los dos enfoques se plantea a continuación.

\section{A. Enfoque academicista}

El enfoque academicista enfatiza en el proceso de selección y organización del contenido; esto es, en los contenidos que aportan las diversas ciencias o disciplinas.

Los objetivos están orientados, fundamentalmente, al desarrollo intelectual de las(os) alumnas(os), en tanto que las estrategias didácticas tienden a garantizar una efectiva transmisión de los contenidos propuestos. Asimismo, se planifican las técnicas tradicionales, como la clase magistral, la lectura de texto, la conferencia, entre otras. En este enfoque, el rol de la y el docente es transmitir a las(os) alumnas(os) el conocimiento, o sea, la educadora o el educador es quien posee y domina el contenido. Esta visión propicia que las y los estudiantes desempeñen un papel pasivo y receptivo.

Con respecto a la evaluación, se recurre a la medición, para determinar cuánto del contenido ha sido asimilado y acumulado por las y los estudiantes.

\section{B. Enfoque constructivista}

En los últimos años, el enfoque constructivista da una nueva visión a los procesos curriculares y a los procesos de enseñanza y aprendizaje en particular. Se sustenta en las teorías cognitivas del aprendizaje. Entre las posiciones que más han influido en el surgimiento de un enfoque curricular constructivista, están las de Ausubel, Piaget y Vigotsky.

La autora Molina (1997:29-30) señala algunos de los aspectos fundamentales del enfoque constructivista:

"El proceso de aprendizaje es continuo y progresivo. Es decir, está en constante evolución. Los niños, adolescentes y adultos aprenden de 
manera significativa y permanente cuando construyen en forma activa sus propios conocimientos.

La inteligencia y la estructuración del pensamiento no son fenómenos que se den sólo como herencia genética; sino también se construyen y evolucionan.

El desarrollo del conocimiento es un proceso, y como tal, se da por etapas que se van alcanzando paulatinamente.

Las experiencias y los conocimientos previos del educando facilitan o inhiben la construcción de nuevos conocimientos.

La base del proceso de construcción del conocimiento está en la acción sobre la realidad, que realiza el sujeto. Esto quiere decir, que el individuo debe entrar directamente en contacto con esa realidad: con los objetos, las personas y los procesos que le interesa conocer [...]".

Sin duda, el planteamiento anterior permite visualizar un cambio radical en el proceso de enseñanza y aprendizaje con respecto al enfoque de corte tradicionalista.

Uno de los cambios que plantea el enfoque constructivista es la manera en que las y los estudiantes asimilan el conocimiento, el cual debe darse en un proceso activo entre educadora o educador y educanda(o) y no simplemente en la concepción de la(del) educanda(o) como un sujeto pasivo; por el contrario, la teoría constructivista pretende la formación de hombres activos, críticos y sin temores para enfrentarse a su entorno y al mundo que le rodea.

La actual Política Educativa "Hacia al Siglo XXI" enfatiza en un cambio de enfoque curricular; sin embargo, cuando se elaboran los programas de estudio en el Ministerio de Educación Pública, estos nuevos planteamientos, muy poco, se toman en cuenta, y la educadora o el educador termina por elaborar su planeamiento desde la perspectiva tradicional, donde sólo se desarrollan los contenidos, sin estimular a la y al estudiante a construir su conocimiento y a ser partícipes en su proceso de enseñanza y aprendizaje.

\section{Planeamiento didáctico}

Uno de los elementos de mayor importancia en la tarea educativa es el planeamiento didáctico. Aunque hay diferentes posiciones en torno a los elementos que deben considerarse en un plan didáctico, para Molina, existen cuatro elementos básicos: objetivos, contenidos, métodos y técnicas y procedimientos de evaluación, que deben estar presentes en todo planeamiento didáctico. 
La autora hace referencia a la forma de tratar estos cuatro elementos, en la etapa de elaboración de los planes didácticos, en el marco del enfoque constructivista.

\section{Objetivos}

En la teoría conductista, los objetivos se visualizan como 'conductas finales' o cambios de conducta. Estos objetivos incluyen conductas observables, que permiten la medición de los resultados y dejan de lado los procesos cognitivos. Cuando se plantea este tipo de objetivos, se espera que todas(os) las(os) alumnas(os) alcancen idénticos resultados, en términos de una conducta previamente establecida con el objetivo. En el enfoque constructivista, por el contrario, cuando se plantean los objetivos, se enfatiza más en el proceso que en el resultado.

Estos objetivos no expresan conductas fijas idénticas, sino que propician y posibilitan las adecuaciones y especificaciones que se requieren en los diferentes niveles de planeamiento. Interesa que en los objetivos se perciban los conocimientos, las habilidades, las destrezas y las pautas de comportamiento que acercarán a las(os) alumnas(os) al logro de persona que se desea formar.

La existencia de diversas posiciones (academicista, constructivista) conlleva también a la existencia de clasificaciones y taxonomías a las que muchas veces la o el docente se inclina por una, sin analizar las implicaciones de asumir una u otra de estas taxonomías, estas generalmente se concentran en el planteamiento de una serie de verbos y se organizan en criterios específicos.

De esta manera, en las visiones conductistas, se seleccionan verbos para elaborar objetivos, tomados de la taxonomía de Bloom. En realidad, las clasificaciones deben ser vistas como un referencial que permita manejar diversos elementos en el momento de elaborar los objetivos que formarán parte de los distintos planes didácticos.

Para Molina (1997:67), los planteamientos de César Coll, en su libro Psicología y currículo, permiten clarificar que el aprendizaje de diferentes tipos de contenidos crea capacidades diferentes y que estos se expresan en los objetivos, especialmente en los verbos utilizados cuando se redactan los objetivos. También presenta un cuadro sobre las taxonomías, en torno a los diversos tipos de contenidos, el significado del aprendizaje y las capacidades o competencias que implica. 
¿Qué significa aprender hechos, conceptos, principios, procedimientos, valores, normas y actitudes, y cómo reflejarlos en los objetivos didácticos?

\section{CATEGORÍA 1 HECHOS, CONCEPTOS Y PRINCIPIOS}

- Aprender hechos y conceptos significa que se es capaz de identificar.

- Reconocer, describir y comparar objetos, sucesos o ideas.

- Aprender un principio significa que se es capaz de identificar, reconocer, clarificar, describir y comparar las relaciones entre los conceptos o hechos a que se refiere el principio.

\section{CATEGORÍA 2 PROCEDIMIENTOS}

- Aprender un procedimiento significa que se es capaz de utilizarlo en diversas situaciones y de diferentes maneras, con el fin de resolver los problemas planteados y alcanzar las metas fijadas.

\section{CATEGORÍA 3 \\ VALORES, NORMAS Y ACTITUDES}

- Aprender un valor significa que se es capaz de regular el propio comportamiento de acuerdo con el principio normativo que dicho valor estipula.

- Aprender una norma significa que se es capaz de comportarse de acuerdo con ella.

- Aprender una actitud significa mostrar una tendencia consistente y persistente a comportarse de una particular manera ante determinada clase de situación, objetos, sucesos o personas.

\section{Verbos que podrían utilizarse para introducir objetivos en las distintas categorías del contenido}

Identificar, analizar, señalar, reconocer, interferir, resumir, clasificar, generalizar, aplicar, describir, comentar, distinguir, comparar, interpretar, relacionar, conocer, recordar, indicar, explicar, sacar soluciones, enumerar, situar (en espacio o tiempo).

Manejar, observar, confeccionar, probar, utilizar, elaborar, construir, simular, aplicar, demostrar, recoger, reconstruir, presentar, planificar, experimentar, ejecutar, componer. 
Comportarse (de acuerdo con), reaccionar a, acceder a, conformarse con, respetar, actuar, preocuparse por, tolerar, conocer, deleitarse, apreciar, darse cuenta que, inclinarse por, prestar, atención a, aceptar, obedecer, interesarse por, ser consciente de, permitir, valorar (positiva o negativamente).

Al plantear los objetivos en diversas categorías, se debe tener presente que:

a. Los verbos utilizados deben tener siempre un referente a un "comportamiento", que se manifiesta en forma amplia y diversa, y no como conducta observable predeterminada.

b. Los mismos verbos pueden, en algunos casos, usarse en diferentes categorías.

c. Un objetivo puede hacer referencia a varios contenidos específicos simultáneamente.

d. Un mismo contenido puede aparecer en varios objetivos, en la medida en que puede ser objeto de diferentes tipos de aprendizajes.

Resulta valioso que las y los docentes recurran a la teoría expuesta por Coll, como un referencial clarificador y orientador. Esta les ayudará a tener mayor claridad en el momento de adquirir un tipo de contenido específico y expresarlo con uno o varios verbos pertinentes.

\section{Contenidos}

En el proceso de enseñanza y aprendizaje, los planteamientos academicistas enfatizan sólo la transmisión y acumulación de conocimientos, lógicamente el rol principal es el contenido.

En cambio, en una visión constructivista, según Molina (1997:86), se asume un proceso de revaloración del contenido en el que se tiende a reivindicar la importancia de este elemento. La posición constructivista surge como una nueva opción, ante la reacción de las posiciones tradicionales, así, las propuestas que se enmarcan dentro de esta alternativa dan énfasis a la creatividad, al descubrimiento y a la construcción, como elementos esenciales en el proceso de aprendizaje.

También, esta posición implica un cambio de actitud en el papel que desempeña la o el docente, pues esta(e) se perfila como una facilitadora o un facilitador o una orientadora o un orientador del proceso de aprendizaje, como una mediadora o un mediador entre el contenido y la estructura cognitiva de la(del) alumna(o). 
La autora Molina (1997:86), para reafirmar esta posición, cita que en el libro Mapas conceptuales, de Antonio Ontoria y otros, se afirma que:

"El profesor es un mediador entre la estructura conceptual de la disciplina y la estructura cognitiva del estudiante. El profesor debe ser un facilitador de los aprendizajes del alumno, una de cuyas funciones consiste en proporcionar al alumno una selección de contenidos culturales significativos, además de unas estrategias que permitan la construcción eficaz de nuevas estructuras cognitivas".

Desde esta perspectiva, Molina (1997) menciona que lo medular es, entonces, plantear el problema del contenido en términos de qué se enseña, cómo se enseña y cómo se aprende.

Ante estas interrogantes, se hace necesario definir qué se entiende por contenido. El autor César Coll (1992:86) define el contenido como "el conjunto de saberes o formas culturales, cuya asimilación y apropiación por los alumnos se considera esencial para su desarrollo y socialización”.

\section{Situaciones de aprendizaje}

Las situaciones de aprendizaje son otro elemento esencial en el planeamiento didáctico. Según Molina (1997:100), algunas(os) estudiosas(os) las han llamado de diversas maneras: situaciones de aprendizaje, actividades, estrategias, experiencias de aprendizaje, estrategias para la medición pedagógica y estrategias didácticas.

De una u otra manera, estos términos se refieren a las acciones que la o el docente prevé y ejecuta para que la(el) alumna(o) pueda desarrollar su proceso de aprendizaje. Las situaciones de aprendizaje varían según el enfoque curricular del que se trate, sea de corte tradicionalista o constructivista. Si se trata de una visión academicista, donde el currículo se centra en la enseñanza, la o el docente enfatizará en las actividades para provocar el aprendizaje; si por el contrario, se enfatiza en una visión constructivista de las actividades, estas se orientan a describir lo que hará la(el) alumna(o) para adquirir o construir su aprendizaje.

Para Molina (1997:102), el término situaciones de aprendizaje "es aquel elemento del currículo que se define como una serie de actividades concatenadas, que permiten al alumno internalizar o construir un determinado aprendizaje". El concepto de "actividades concatenadas" remite a que la(el) alumna(o) realice alguna actividad previa para recordar algunos conocimientos básicos 
sobre el objeto de estudio, y luego las diferentes actividades que hace le permite ampliar sus conocimientos, aplicar lo aprendido, buscar respuestas nuevas y transferir lo aprendido a nuevas situaciones.

\section{Evaluación}

En el planeamiento didáctico, la evaluación se constituye en una parte integral del proceso de enseñanza y aprendizaje en el aula. Es necesario establecer la diferencia entre evaluación y medición, términos que se suelen confundir, porque se usan con el mismo significado.

Al respecto, Molina (1997:108), para establecer la diferencia entre evaluación y medición, recurre a la definición que da el autor Mager; este define la medición como "un proceso para determinar el grado o amplitud de alguna característica asociada con un objeto o persona”. Mientras que evaluación, el mismo Mager la define como "el acto de comparar una medida con un estándar y emitir un juicio basado en la comparación” (pág. 109).

De lo anterior se desprende que la medición y la evaluación son dos procesos diferentes, pero que se complementan. Cuando se hace referencia a la evaluación como elemento constitutivo del planeamiento didáctico, esta debe asumirse como un proceso sistemático de reflexión sobre la propia práctica. En este sentido, la evaluación debe ser utilizada para retroalimentar esa práctica. Tal proceso evaluativo permite analizar características, condiciones y logros de las(os) alumnas(os), ritmos de aprendizaje; pero, fundamentalmente, examinar la evaluación del aprendizaje adquirido o construido por las y los estudiantes.

De esta manera, hay que tener presente que no es igual evaluar un dato, hecho, concepto o principio, que un procedimiento, una actitud o un valor. En los casos de datos, hechos, conceptos o principios es de esperar que mediante la evaluación, las(os) alumnas(os) ofrezcan información ya adquirida. Basta con una pregunta para saber si una alumna o un alumno conoce o no un dato o un determinado hecho. Cuando se trata de comprender un concepto, de aplicar un principio, de desarrollar un procedimiento, una actitud o un valor, la adquisición del aprendizaje puede tener diferentes grados. Por otra parte, es relevante que las(os) alumnas(os) expliquen y que no repitan textualmente. Es necesario que los conceptos y los principios sean evaluados en situaciones determinadas.

En los procedimientos, lo importante es que las(os) alumnas(os) sepan ejecutarlos, se trata de demostrar su capacidad para aplicar y adecuar el aprendizaje a nuevas situaciones. Las actividades y los valores son los aspectos más difíciles de evaluar. Aunque hay instrumentos estandarizados (escalas principalmente) para evaluar actitudes y valores, no existe acuerdo entre las(os) 
estudiosas(os) sobre la validez para aplicar este instrumento como algo unificado, sin considerar cada caso en particular y cada contexto específico.

Ante esta duda, surge la alternativa de planificar técnicas evaluativas variadas y novedosas, que permitan a las(os) alumnas(os) manifestarse y a las y los docentes percibir el logro de determinada actitud o valor y recoger la información mediante hojas de observación, listas de cotejo o escalas elaboradas por las(os) mismas(os) docentes.

La observación permanente constituye una estrategia importante en la evaluación del aprendizaje; no obstante, es necesario que la o el docente tenga a mano instrumentos para anotar estas observaciones. Para ello, se deben tomar en cuenta los nuevos estudios y teorías, que proponen novedosas técnicas, tal es el caso de la Teoría de las Inteligencias Múltiples.

\section{Teoría de las Inteligencias Múltiples}

La inteligencia que posee el ser humano le proporciona razonar, interpretar, asociar y discernir cosas, objetos o situaciones experimentadas en su entorno. Esa capacidad le permite distinguir la realidad del sueño, el bien del mal, las letras de los números y la posibilidad de escoger una opción entre varias para solucionar una dificultad.

Según Antunes (1998:9), la inteligencia se define como la capacidad cerebral por la cual conseguimos penetrar en la comprensión de las cosas eligiendo el mejor camino. La escogencia de una solución adecuada permite que el ser humano tome en cuenta su medio, cultura, costumbres, valores y otros ambientes que van a influir en sus decisiones y que, a su vez, le proporcionará un mayor grado de comprensión.

Además, el medio en que se desenvuelve el ser humano será vital, no sólo para la solución de una dificultad, sino para aumentar sus habilidades o, por el contrario, no le favorecerá el aumento de ellas. Para obtener lo primero, es necesaria la estimulación de esas habilidades que se conocen como inteligencias múltiples.

En los últimos años, las investigaciones y los descubrimientos sobre el comportamiento del cerebro revelan que no sólo existe una inteligencia que se enfoca en el almacenamiento de conocimiento (cognitivo), sino que hay muchos tipos de inteligencia que los seres humanos tienen.

El ser humano posee cada una de las inteligencias, pero hay unas más desarrolladas que otras. Las diferentes inteligencias nacen de la Teoría de las Inteligencias Múltiples, postulada por el Dr. Howard Garner. Las inteligencias múltiples son una serie de habilidades que tiene el ser humano para resolver problemas, o producir resultados, para satisfacer una necesidad humana. 


\section{Factores que aumentan las inteligencias múltiples}

Existen diversos factores que inciden en el desarrollo o crecimiento de cada una de las inteligencias, entre ellos están:

1. Predisposición genética.

2. Estimulación temprana.

3. Forma creativa de enseñar métodos y técnicas.

4. Creación de ambientes estimulantes y armoniosos para su aprendizaje.

\section{Tipos de inteligencias múltiples}

1. Lingüística: sensibilidad a los sonidos, estructura, significados y funciones de las palabras y el lenguaje.

2. Lógico-matemática: sensibilidad y capacidad de distinguir patrones lógicos o numéricos, habilidad de manejar largos hilos de razonamiento.

3. Espacial: capacidad para percibir acertadamente el mundo visual y espacial y para realizar transformaciones sobre las percepciones iniciales propias.

4. Física y Kinésica: habilidad para controlar los movimientos del cuerpo propio y para manipular objetos con destreza.

5. Musical: habilidad para producir y apreciar ritmo, tono y timbre; apreciación de las formas de expresión musical.

6. Interpersonal: capacidad para discernir y responder adecuadamente a los estados de ánimo, temperamentos, motivaciones y deseos de otras personas.

7. Intrapersonal: acceso a los sentimientos propios y la habilidad para discernir las emociones íntimas; conocimientos de las fortalezas y debilidades propias.

\section{Posición teórica sobre las inteligencias múltiples}

Durante mucho tiempo, se creyó que la persona inteligente era la única que tenía desarrolladas dos habilidades: la verbal o lingüística y la lógico-matemática. Los recientes estudios sobre el desarrollo potencial de las inteligencias en las personas han demostrado que cada individuo aprende de formas diversas y posee una serie de habilidades, donde se destaca en una o varias de ellas. Su estimulación depende del interés que tengan tanto las madres y los padres de familia como las y los docentes en incentivarlas. 
Para que la o el docente obtenga éxito en la aplicación de nuevas técnicas educativas, debe asegurarse que la y el estudiante se familiarice con la técnica hasta el punto que logre desarrollarla con independencia, seguridad y creatividad. Cada una de ellas tiene una explicación lógica y una relación con la inteligencia múltiple. Además, tienen relaciones estrechas con el desarrollo educativo. Según Celso A. Antunes (1998:112):

\begin{abstract}
"Al descubrir que podemos construir imágenes verbales mucho más amplias y completas que las que habitualmente creamos, al sentir que las viejas matemáticas de los libros de texto pueden desaparecer para volver a descubrir la matematización de nuestras relaciones ambientales, al liberar los límites de nuestra creatividad y, a través de esa liberación, alcanzar planos más amplios de una visión del mundo mediante nuestra inteligencia espacial, al aceptar que somos limitados, sólo por cuanto, en el dominio de nuestra concentración, de nuestra sensibilidad táctil, de nuestra audición o de nuestro sentido del gusto, avanzamos muy poco en el descubrimiento de la naturaleza o en el control de nuestras relaciones interpersonales e intrapersonales estamos dando simplemente una respuesta coherente a por qué estimular nuestras inteligencias, las de nuestros hijos o las de nuestros alumnos".
\end{abstract}

Para el desarrollo de las inteligencias múltiples, es necesaria la aplicación de técnicas novedosas que faciliten y hagan más dinámico el aprendizaje en áreas como el razonamiento abstracto, la lectoescritura y la matemática.

\title{
Procedimiento metodológico
}

El proceso investigativo estuvo enmarcado en el enfoque cualitativo, tal y como lo plantea Barrantes (1999) cuando afirma que este enfoque busca descubrir o generar teorías más que verificarlas o comprobarlas.

Por tal motivo, el propósito fue descubrir el proceso de enseñanza y aprendizaje que se realiza cuando se lee y analiza la obra literaria El Ingenioso $\mathrm{Hi}$ dalgo Don Quijote de la Mancha, en la enseñanza secundaria. La investigación se caracterizó por ser descriptiva, es decir, se recogió información pertinente acerca del objeto de investigación; se tabularon, analizaron e interpretaron los datos con el objetivo de descubrir el problema que evidencian las y los docentes cuando estudian la obra literaria de Miguel de Cervantes. El que fuera de este tipo, permitió describir las técnicas que utilizan las(os) profesoras(es) de español para estudiar y evaluar la obra literaria El Ingenioso Hidalgo 
Don Quijote de la Mancha y determinar si estas eran adecuadas para desarrollar el proceso de enseñanza y aprendizaje con las y los discentes.

Las y los participantes fueron docentes y estudiantes de dos reconocidas instituciones educativas, de la provincia de Heredia. Se trabajó con una pequeña muestra en cada institución. En el caso de las y los estudiantes, se trabajó con cinco informantes que cursaban el nivel de décimo año. Mientras que con las y los docentes, participaron una o uno de cada institución y que tuvieran a cargo décimo año.

Hubo complementariedad de métodos cualitativos y cuantitativos, con el fin de enriquecer el proceso, por lo tanto, los instrumentos aplicados fueron elaborados con preguntas abiertas, semiabiertas y cerradas. En relación con la aplicación de los instrumentos, se realizó una observación no participante en cada institución seleccionada. Para ello, se diseñó una ficha de observación conformada por tres partes. Cada parte presentó una serie de preguntas estructuradas que estaban relacionadas con las situaciones que se presentan en el salón de clase.

La primera parte contenía información para identificar el enfoque de enseñanza y aprendizaje usado por la o el docente. La segunda era una guía para conocer las actividades y técnicas de enseñanza. La última parte recopilaba información acerca del trato de la o el docente hacia las(os) educandas(os). También se elaboró una ficha de observación dirigida a la y el estudiante para conocer el área afectiva durante la clase, las actividades que realizaba y las actitudes ante las técnicas de enseñanza aplicadas por la o el docente.

El otro instrumento aplicado fue el cuestionario. Se elaboró uno para las y los docentes y otro dirigido a las y los estudiantes. El primer instrumento se dividió en dos partes: una que recogía información general de la o el docente y la otra estaba orientada a recopilar información acerca de las técnicas de enseñanza usadas por la educadora o el educador para el análisis de la obra literaria El Ingenioso Hidalgo Don Quijote de la Mancha.

El segundo cuestionario dirigido a las y los estudiantes estaba estructurado en dos secciones: una recopilaba información general y la otra recogía información acerca de métodos y técnicas usados por las o los docentes para el estudio de la obra de Miguel de Cervantes.

Por otra parte, la información recopilada se ordenó, tabuló y contrastó mediante la técnica cualitativa llamada triangulación. Se consideraron cinco unidades de análisis:

1. Opiniones de las y los estudiantes acerca de las clases de español.

2. El enfoque de enseñanza y aprendizaje utilizado por la profesora o el profesor. 
3. Los métodos y técnicas que utiliza la profesora o el profesor en el salón de clase cuando estudia la obra literaria El Ingenioso Hidalgo Don Quijote de la Mancha.

4. Las técnicas de evaluación más utilizadas por la profesora o el profesor cuando evalúa la novela El Ingenioso Hidalgo Don Quijote de la Mancha.

5. En la parte socioafectiva, cómo afectan a las y los estudiantes los métodos y técnicas empleados por la o el docente.

\section{Principales conclusiones}

Las principales conclusiones que se obtuvieron del proceso investigativo se describen a continuación:

- Las técnicas y estrategias metodológicas empleadas por la o el docente para el estudio de una obra literaria influyen en la percepción positiva o negativa que tienen las y los estudiantes de las clases de español y, principalmente, cuando se estudia la novela El Ingenioso Hidalgo Don Quijote de la Mancha.

- La educadora o el educador sigue utilizando técnicas rutinarias, poco motivadoras y sin un claro objetivo, que impiden que la o el discente sea partícipe y constructora o constructor de su propio conocimiento.

- La mayor parte del tiempo lectivo, las y los estudiantes se limitan a escuchar, memorizar y repetir los datos e información brindados por los libros y las(os) profesoras(es). Definitivamente, el papel asumido por las(os) alumnas(os) produce un estado de pasividad, lo cual hace que el español represente para ellas(os) una asignatura aburrida, cansada y poco interesante.

- Las(os) docentes entrevistadas(os) tienen claro que su función principal es la de ser guías o facilitadoras(es) del proceso de enseñanza y aprendizaje; sin embargo, siguen siendo transmisoras(es) de conocimientos.

- Una de las técnicas más utilizadas es la del cuestionario. La o el docente prepara una guía de estudio acerca de la obra y las y los estudiantes proceden a contestarla en subgrupos.

- Las principales desventajas detectadas, durante la investigación, acerca del uso del cuestionario, se resumen en que la o el discente transcribe solamente información de un texto, no estimula la creatividad, produce desmotivación y falta de interés por la asignatura.

- Si la educadora o el educador promueve una metodología participativa, dinámica e innovadora, las y los estudiantes responden positivamente $\mathrm{y}$ 
se sienten un poco más cautivadas(os) en relación con el estudio de la novela de Miguel de Cervantes.

- El instrumento o técnica evaluativa más utilizada por los y las docentes para valorar los aprendizajes es la prueba escrita (función sumativa).

- La forma o la manera de enseñar del y la docente incide en el bajo rendimiento de las y los estudiantes, porque ellas(os) deben estar motivadas(os) para interesarse por la asignatura.

- Las principales causas que no estimulan a la o el discente para leer la novela El Ingenioso Hidalgo Don Quijote de la Mancha son los horarios recargados y la falta de hábitos de lectura, según la información proporcionada por las y los docentes-informantes.

- Las técnicas de enseñanza usadas en el área de español se enmarcan dentro del enfoque conductista.

- La o el docente no evalúa, sino que mide productos finales mediante pruebas escritas, ya que estas solo refuerzan el sistema memorístico y no los aspectos creativo, crítico, reflexivo o analítico de las o los discentes.

- Las y los estudiantes perciben las lecciones de español y específicamente el estudio de la obra El Ingenioso Hidalgo Don Quijote de la Mancha como aburridas, cansadas y poco interesantes.

\section{Recomendaciones finales}

Con base en los resultados finales, se proponen las siguientes recomendaciones a las y los docentes de secundaria, al Ministerio de Educación Pública y otras instituciones de carácter educativo.

En relación con las y los docentes, deben tener claro que la forma de conducir el proceso de enseñanza y aprendizaje es fundamental, por lo tanto, se recomienda:

- Participar en procesos de capacitación y refrescamiento acerca de nuevas tendencias educativas y estrategias novedosas para la promoción, animación y la interpretación de textos literarios, lo cual permitiría tener un criterio para guiar su labor educativa.

- Propiciar un ambiente agradable y cordial, que permita mantener buenas relaciones entre docente y estudiantes, puesto que el trato influye positiva o negativamente en el proceso de aprendizaje de las y los discentes.

- Orientar el proceso de enseñanza y aprendizaje con optimismo e interés, ya que su manera de actuar se ve reflejada en el trabajo que las(os) educandas(os) realizan. Debe ser una persona abierta, dispuesta al cambio, sensible a los problemas que aquejan a las y los estudiantes. 
- Considerar, en el proceso educativo, no sólo los contenidos curriculares de cada área del saber, sino contemplar los contenidos culturales, es decir, todo aquel conocimiento y experiencias del entomo.

Por otra parte, al Ministerio de Educación Pública se le presentan las siguientes recomendaciones:

- Debe buscar una forma para capacitar a las y los docentes en áreas prioritarias, no es suficiente enviar los documentos a los colegios para ser leídos. Debe considerar otros mecanismos de capacitación y estar atento si se cumplen los nuevos conocimientos adquiridos.

- Lo importante es que la o el docente comprenda que la sociedad actual le exige estar atenta(o) a los cambios y, solamente a través de la constante renovación de conocimientos, puede hacerle frente a todos estos retos.

\section{Propuesta metodológica para la interpretación y el análisis de la obra lite- raria El Ingenioso Hidalgo Don Quijote de la Mancha}

Constituye una unidad didáctica y una serie de técnicas educativas que contribuyen a mejorar la calidad de la enseñanza del español, en particular, cambiar la percepción negativa que tienen las y los estudiantes sobre la lectura de la obra cumbre de Miguel de Cervantes. La propuesta responde a las diversas necesidades que enfrenta, actualmente, nuestro sistema educativo.

Las y los docentes como facilitadores del proceso de enseñanza y aprendizaje juegan un papel primordial en el desarrollo de las diversas situaciones de aprendizaje que prevén y ejecutan en el salón de clase, ya que la metodología y las técnicas educativas que usen pueden ser percibidas por la y el estudiante de una forma positiva o negativa. Ahí se ubica la raíz del problema. Esto significa que la mayor responsabilidad recae en la educadora o el educador, no porque la calidad de lo que imparte sea mala, sino que, como ya se conoce desde años atrás, el conductismo es una de las causas que conlleva al deterioro en la educación.

Por tal motivo, la educadora o el educador debe romper con la rigidez y la inflexibilidad del sistema educativo, porque este oprime tanto a la o el docente como a la o el estudiante. Para cumplir estas metas, cada docente debe prepararse bien, asumir una actitud positiva ante el cambio y la innovación. Esta nueva apertura permitirá recuperar la calidad de la educación, a pesar del gran aumento de los contenidos del programa.

La preparación de las y los docentes debe estar basada en los valores fundamentales que le permiten a estas(os) y a las y los estudiantes realimentarse, no sólo de conocimiento, sino también de las vivencias de cada una(o), 
pues ambas(os) son sujetos que forman parte importante del proceso de enseñanza y aprendizaje. Por ello, requieren de capacitaciones periódicas y la actualización constante en nuevas metodologías didácticas que sirvan de herramienta para incentivar en el salón de clase la comunicación, la motivación, el interés, la creatividad y la libertad de construir el conocimiento. Pero ese compromiso no sólo es para educadoras(es); involucra a las universidades, que como bien se ha escuchado y comprobado, su calidad y el nivel de preparación que reciben las(os) futuras(os) profesionales son inadecuados. También se unen a ellas las(os) asesoras(es) y el Ministerio de Educación Pública.

Todas(os) ellas(os) tienen que trabajar conjuntamente para iniciar proyectos que mejoren la calidad de las y los profesionales, de la educación y cumplan con las expectativas y necesidades de la población estudiantil.

La propuesta es de interés para las universidades, las(os) asesoras(es) y Ministerio de Educación Pública, porque sirve de punto de partida para la formación de las(os) futuras(os) profesionales. Estas entidades tienen el compromiso de realizar un análisis profundo del grave problema de la calidad de la educación, con el fin de fortalecerla con buenas iniciativas para llegar a mejores soluciones, como por ejemplo, propuestas innovadoras, puesta en práctica de metodologías didácticas y capacitación permanente a docentes.

El objetivo fundamental del trabajo de investigación es que el y la docente innoven y desarrollen en el salón de clase las obras literarias propuestas por el Ministerio de Educación Pública, con una moderna y participativa metodología didáctica. Se pretende con ello que la o el estudiante "deseche" su actitud negativa hacia la lectura de obras literarias y, en particular, por la novela $E l$ Ingenioso Hidalgo Don Quijote de la Mancha. La propuesta no presenta una serie de soluciones inmediatas, sino una opción, un material de apoyo que debe analizarse y evaluarse.

A continuación, se presenta la descripción de una serie de técnicas educativas innovadoras que le permitirá a la o el docente, que imparte los niveles de décimo o undécimo año, mejorar el desarrollo del proceso educativo, específicamente con la lectura de la novela El Ingenioso Hidalgo Don Quijote de la Mancha. Se adjunta también la unidad didáctica respectiva.

Estrategia 1: Siguiendo la ruta de Don Quijote.

Inteligencias múltiples que incentiva: Espacial, Pictórica, Lingüística, Lógico-matemática.

Materiales: Cartulina o papel periódico, revistas, goma,tijeras, regla, cinta, lápices de colores, marcadores, papel de construcción o satinado, hojas blancas.

La estrategia le permite a la o el estudiante comprender, familiarizarse y darle vida a la historia de Don Quijote y su escudero. Puede ser utilizada para desarrollar los siguientes temas: 
A. Espacios físicos que recorrieron Don Quijote y Sancho Panza.

B. El itinerario de Don Quijote: las aventuras de Don Quijote en tres salidas y en tres episodios. (Objetivo específico \# 1.1 de la Unidad Didáctica).

Las inteligencias múltiples que estimula son cuatro. La pictórica le ayuda a la y el estudiante a describir con ilustraciones pasajes, escenas o acontecimientos relevantes de la obra literaria El Ingenioso Hidalgo Don Quijote de la Mancha. Desarrolla la creatividad y la imaginación, para darle vida a la historia que creó Miguel de Cervantes.

La espacial le permite a la y el estudiante mirar el mapa no como una fotografía estática del espacio simbolizado, sino como una escena vibrante de los lugares geográficos que recorrió Don Quijote con su escudero en busca de aventuras y de deshacer agravios. Las regiones de España que recorrió Don Quijote y que se ilustran en el mapa se transforman y empiezan a adquirir historicidad; es decir, recobra vida la realidad descrita y plasmada de los lugares y paisajes citados por Cervantes en su obra.

La lingüística fomenta la expresión oral en las y los estudiantes y la lógico-matemática les permite organizar cronológicamente los acontecimientos relevantes de la obra literaria en estudio.

\section{Pasos}

1. Se forman subgrupos de cinco personas.

2. Se le asigna a cada subgrupo cinco aventuras que pueden ser de la primera o segunda parte de la obra cumbre de Cervantes. (La elección depende del nivel que esté impartiendo la o el docente).

3. Cada subgrupo dibuja el mapa de España en una cartulina o papel periódico.

4. De acuerdo con la lectura realizada de la novela, el subgrupo traza con una línea los lugares que visitó, en los cinco capítulos que se les asignó.

5. Dibujan los personajes más representativos que participaron en las locuras del caballero andante, además, de las figuras de Don Quijote y su escudero.

6. Cada grupo nombra una relatora o un relator, quien narrará breve y cronológicamente los acontecimientos vividos por Don Quijote.

La relatora o el relator también tiene que señalar mientras narra, el lugar y los personajes que intervienen en la aventura. Las figuras deben pegarse en el espacio correcto para ir enlazando en forma coherente la historia. Se recomienda 
dejar los mapas con las figuras exhibiéndose en el salón de clase para que sirvan posteriormente para repasar la obra literaria.

\section{Evaluación}

La elaboración de los materiales se asigna como un trabajo extraclase y la exposición de cada grupo puede formar parte del valor porcentual del trabajo cotidiano o evaluarla como un rubro más del trabajo extraclase.

La siguiente lista de cotejo puede ser de utilidad para la evaluación de la técnica y el desarrollo de sus temas.

\begin{tabular}{|c|c|c|c|c|c|c|}
\hline Rubros & 1 & 2 & 3 & 4 & 5 & Total \\
\hline \multicolumn{7}{|l|}{ Presentación del trabajo completo. } \\
\hline \multicolumn{7}{|l|}{$\begin{array}{l}\text { Creatividad (la presentación del mapa, los } \\
\text { dibujos de los personajes si fueron dise- } \\
\text { ñados por las y los estudiantes o extraídos } \\
\text { de Internet o de revistas). }\end{array}$} \\
\hline \multicolumn{7}{|l|}{$\begin{array}{l}\text { Aportación de materiales e ideas para de- } \\
\text { sarrollar la técnica. }\end{array}$} \\
\hline \multicolumn{7}{|l|}{$\begin{array}{l}\text { Expresión oral (dicción, proyección de la } \\
\text { voz, fluidez, expresión corporal). }\end{array}$} \\
\hline \multicolumn{7}{|l|}{ Organización cronológica de las aventuras. } \\
\hline \multicolumn{7}{|l|}{$\begin{array}{l}\text { Localización en el espacio de los lugares que } \\
\text { recorrieron Don Quijote y su escudero. }\end{array}$} \\
\hline \multicolumn{7}{|l|}{$\begin{array}{l}\text { Reproducción de los espacios geográficos } \\
\text { en un mapa. }\end{array}$} \\
\hline \multicolumn{7}{|l|}{$\begin{array}{l}\text { Facilidad en la narración, la descripción y } \\
\text { el resumen de las aventuras. }\end{array}$} \\
\hline Total & & & & & & \\
\hline
\end{tabular}


Estrategia 2: El mundo quijotesco en caricatura.

Inteligencias múltiples que incentiva: Pictórica, Lingüística.

Materiales: Cartulina o papel periódico, hojas blancas, papel de construcción, revistas, lápices de colores, marcadores, tijeras, goma.

La estrategia retrata mediante dibujos o caricaturas la variedad temática que presenta la obra literaria de Cervantes. Las caricaturas le permiten a la y el estudiante hilar los temas secundarios con el tema central. Los contenidos que se pueden desarrollar con esta técnica son:

A. Temas central y secundarios de la obra literaria cervantina. (Objetivos específicos \# 2.1, 2.2 de la Unidad Didáctica).

B. Las dicotomías y los estilos del lenguaje. (Objetivos específicos \# 2.3, 2.4 de la Unidad Didáctica).

Las dos inteligencias múltiples que se estimulan con la utilización de esta estrategia le permiten a la o el estudiante expresar oralmente y con dibujos la diversidad temática que se entreteje en la novela.

\section{Pasos}

1. Se divide el grupo en once subgrupos.

2. Se le asigna a cada subgrupo un tema de la lectura de la obra literaria $E l$ Ingenioso Hidalgo Don Quijote de la Mancha.

3. Cada subgrupo analiza el tema. Discute como lo van a representar gráficamente.

4. Los subgrupos inician la elaboración del material didáctico que necesitan para desarrollar la técnica.

5. Posteriormente, cada subgrupo prepara una breve explicación del tema que se le asignó, utilizando las ilustraciones para una mayor comprensión.

Esta estrategia le da libertad a las y los estudiantes para que decidan como van a realizar las ilustraciones y su exposición. El dibujo o caricatura que se realiza de cada tema debe tener una secuencia que sintetice los aspectos más importantes de ella. También puede ser usada para la elaboración de títeres de papel. Para su construcción, deben delimitar quiénes serán los personajes relevantes que representarán el tema en estudio. Luego caricaturizarán los personajes en cartulina u hojas blancas y las pegarán en pequeñas bolsas de papel, en medias o en paletas. Finalmente, realizarán ante el grupo una pequeña función 
de títeres que expondrá de forma jocosa los acontecimientos que se indican en el tema asignado.

\section{Evaluación}

La elaboración de los materiales se asigna como un trabajo extraclase y la exposición de cada grupo puede formar parte del valor porcentual del trabajo cotidiano o evaluarla como un rubro más del trabajo extraclase.

La siguiente lista de cotejo puede ser de utilidad para la evaluación de la técnica y el desarrollo de sus temas.

\begin{tabular}{|c|c|c|c|c|c|c|}
\hline Rubros & 1 & 2 & 3 & 4 & 5 & Total \\
\hline \multicolumn{7}{|l|}{ Presentación del trabajo completo. } \\
\hline \multicolumn{7}{|l|}{$\begin{array}{l}\text { Creatividad (la construcción de las cari- } \\
\text { caturas y el método que utilizaron para la } \\
\text { exposición). }\end{array}$} \\
\hline \multicolumn{7}{|l|}{$\begin{array}{l}\text { Aportación de materiales e ideas para de- } \\
\text { sarrollar la técnica. }\end{array}$} \\
\hline \multicolumn{7}{|l|}{$\begin{array}{l}\text { Expresión oral (dicción, proyección de la } \\
\text { voz, fluidez). }\end{array}$} \\
\hline \multicolumn{7}{|l|}{$\begin{array}{l}\text { Reproducción por medio de dibujos, cari- } \\
\text { caturas o títeres de un acontecimiento de } \\
\text { la novela. }\end{array}$} \\
\hline \multicolumn{7}{|l|}{$\begin{array}{l}\text { Facilidad en la narración, descripción y } \\
\text { resumen de los sucesos más importantes } \\
\text { de la obra literaria en estudio. }\end{array}$} \\
\hline Total & & & & & & \\
\hline
\end{tabular}


Estrategia 3: Cancionero de La Mancha.

Inteligencias múltiples que incentiva: Musical, Linguiística.

Materiales: Hojas, lápices, casete, grabadora.

La estrategia le permite a las y los estudiantes expresar emociones, sentimientos y puntos de vistas acerca de la novela, por ejemplo, escribir una canción que presente una crítica a la lectura de los libros de caballería, al ideal caballeresco y al papel de la Iglesia (Inquisición). Los contenidos que se desarrollarán con esta técnica son:

A. Diferencias de expresión según la índole de los personajes. (Objetivo general \# 3 de la Unidad Didáctica).

B. Expresiones lingüísticas de la época. (Objetivos específicos \# 3.1, 3.2 de la Unidad Didáctica).

C. Relación de los personajes de las historias insertadas con personajes principales. (Objetivo específico \# 4.2 de la Unidad Didáctica).

La estrategia estimula dos inteligencias múltiples: lingüística y musical. Esta última es la predominante. Ambas producen en las y los estudiantes espontaneidad y fluidez verbal. Las canciones las pueden desarrollar espontáneamente o grabarlas en un casete.

\section{Pasos}

1. Se divide el grupo en cinco subgrupos.

2. Cada subgrupo selecciona un tema que será proporcionado por la o el docente.

3. Cada grupo analiza y discute el tema dado por la o el docente.

4. Las y los estudiantes escriben la letra de la canción con el tema seleccionado.

5. Luego le inventan a la canción un ritmo.

6. Cada subgrupo expone su trabajo al resto del grupo.

\section{Evaluación}

La elaboración de los materiales se asigna como un trabajo extraclase y la exposición de cada grupo puede formar parte del valor porcentual del trabajo cotidiano o evaluarla como un rubro más del trabajo extraclase.

La siguiente lista de cotejo puede ser de utilidad para la evaluación de la técnica y el desarrollo de sus temas. 


\begin{tabular}{l|l|l|l|l|l|l}
\hline Rubros & 1 & 2 & 3 & 4 & 5 & Total \\
\hline Presentación del trabajo completo. & & & & & & \\
\hline $\begin{array}{l}\text { Creatividad en la elaboración de una can- } \\
\text { ción y su ritmo. }\end{array}$ & & & & & & \\
\hline $\begin{array}{l}\text { Aportación de materiales e ideas para de- } \\
\text { sarrollar la técnica. }\end{array}$ & & & & & & \\
\hline $\begin{array}{l}\text { Expresión oral (proyección de la voz, } \\
\text { fluidez, buena dicción). }\end{array}$ & & & & & & \\
\hline $\begin{array}{l}\text { Facilidad en la interpretación de la can- } \\
\text { ción. }\end{array}$ & & & & & & \\
\hline \begin{tabular}{l} 
Total \\
\hline
\end{tabular}
\end{tabular}

Estrategia 4: La sátira de Don Quijote de la Mancha.

Inteligencias múltiples que incentiva: Musical, Lingüística, Kinestésicacorporal.

Materiales: Recurso humano.

La estrategia anima a las y los estudiantes a inventar parodias sobre la obra literaria El Ingenioso Hidalgo Don Quijote de la Mancha. Fomenta la creatividad y la espontaneidad en las y los estudiantes cuando realizan una imitación burlesca de los personajes o de alguna aventura de la obra cumbre de Cervantes. Los temas que se pueden utilizar para el desarrollo de esta técnica son:

A. Estilos del lenguaje. (Objetivo específico \# 2.4 de la Unidad Didáctica).

B. Dicotomías. (Objetivo específico \# 2.3 de la Unidad Didáctica).

C. Tipos de lenguaje. (Objetivo general \# 3 de la Unidad Didáctica).

D. Expresiones populares y refranes. (Objetivo específico \# 3.1 de la Unidad Didáctica).

E. Historias insertadas. (Objetivo específico \# 4.1 de la Unidad Didáctica).

F. Relación de los personajes de historias insertadas con personajes principales. (Objetivo específico \# 4.2 de la Unidad Didáctica). 
Esta estrategia estimula básicamente la habilidad musical, pero también desarrolla otras habilidades como la lingüística y la kinestésica-corporal.

\section{Pasos}

1. Se divide el grupo en siete subgrupos.

2. Se le asigna a cada subgrupo un tema.

3. Cada subgrupo analiza, discute y planea como va a realizar la imitación burlesca de la obra literaria El Ingenioso Hidalgo Don Quijote de la Mancha.

4. Cada subgrupo realiza la representación teatral para ridiculizar algún pasaje de una aventura y la forma de hablar de uno o varios de los - personajes.

5. Finalmente se realiza una mesa redonda para discutir las experiencias y los conocimientos que adquirieron con las parodias que crearon de algún pasaje de la obra literaria en estudio.

La estrategia estimula la creatividad, la expresión oral y corporal, la libertad y las relaciones humanas entre las y los estudiantes.

La creación de parodias referidas a algún pasaje o personaje de la obra literaria en estudio puede realizarse en forma espontánea o prepararla con mayor tiempo, es decir, las y los estudiantes pueden utilizar una cámara de vídeo (si se tiene acceso a ella) para grabar la parodia que crearon. Para ello, es necesario buscar un escenario, vestuario y escribir un pequeño guión. Luego, la presentan al resto del grupo.

\section{Evaluación}

La elaboración de los materiales se asigna como un trabajo extraclase y la exposición de cada grupo puede formar parte del valor porcentual del trabajo cotidiano o evaluarla como un rubro más del trabajo extraclase.

La siguiente lista de cotejo puede ser de utilidad para la evaluación de la técnica y el desarrollo de sus temas. 


\begin{tabular}{|c|c|c|c|c|c|c|}
\hline Rubros & 1 & 2 & 3 & 4 & 5 & Total \\
\hline \multicolumn{7}{|l|}{ Presentación del trabajo completo. } \\
\hline \multicolumn{7}{|l|}{ Creatividad en la elaboración de parodias. } \\
\hline \multicolumn{7}{|l|}{$\begin{array}{l}\text { Aportación de materiales e ideas para de- } \\
\text { sarrollar la técnica. }\end{array}$} \\
\hline \multicolumn{7}{|l|}{$\begin{array}{l}\text { Expresión oral (proyección de la voz, } \\
\text { fluidez, buena dicción). }\end{array}$} \\
\hline \multicolumn{7}{|l|}{$\begin{array}{l}\text { Interpretación de una imitación burlesca } \\
\text { de algún tema, aventura o la forma de ha- } \\
\text { blar de un personaje. }\end{array}$} \\
\hline \multicolumn{7}{|l|}{$\begin{array}{l}\text { Demuestra por medio de la expresión cor- } \\
\text { poral una parodia. }\end{array}$} \\
\hline \multicolumn{7}{|l|}{$\begin{array}{l}\text { Interactúa con sus compañeros en la pre- } \\
\text { sentación de las parodias. }\end{array}$} \\
\hline Total & & & & & & \\
\hline
\end{tabular}

Estrategia 5: El ecléctico mundo de Don Quijote y Sancho Panza.

Inteligencias múltiples que incentiva: Lingüística, Kinestésica-corporal, Pictórica.

Materiales: Recurso humano, papel periódico, bolsas para basura, papel china, videograbadora, casete para vídeo, cosméticos.

La estrategia le permite a la o el estudiante reconstruir un pasaje de la obra literaria El Ingenioso Hidalgo Don Quijote de la Mancha con libertad y creatividad. También se destaca la habilidad pictórica cuando construye su propio vestuario para realizar la representación teatral, por ejemplo, la elaboración de las máscaras.Los temas que se pueden utilizar para el desarrollo de esta técnica son:

A. Historias insertadas. (Objetivo específico \# 4.1 de la Unidad Didáctica). 
B. Relación de los personajes de historias insertadas con los personajes principales. (Objetivo específico \# 4.2 de la Unidad Didáctica).

C. Temas principales y secundarios. (Objetivos específicos \# 2.1, 1.2 de la Unidad Didáctica).

D. Dicotomías y estilos del lenguaje. (Objetivos específicos \# 2.3, 2.4 de la Unidad Didáctica).

\section{Pasos}

1. Se divide el grupo en siete subgrupos.

2. Se le asigna un tema a cada subgrupo y estos preparan su representación. Para ello, discuten sobre el tema, se reparten los personajes y planean como desarrollarlo en el salón de clase.

3. Cada grupo define como será su representación, por ejemplo, un grupo puede representar el tema asignado utilizando máscaras, otro grabará la representación en otro espacio y luego la presentará al grupo, entre otras formas.

4. Cada subgrupo expone ante el resto del grupo su representación y posteriormente, se realiza un pequeño comentario crítico de lo que representaron.

La estrategia permite a la y el estudiante realizar representaciones teatrales innovadoras, como grabar con una cámara de vídeo y en un lugar fuera del aula alguna de las aventuras de la novela. También puede inventar una entrevista, donde el invitado estelar será Don Quijote u otro personaje de la novela.

\section{Evaluación}

La elaboración de los materiales se asigna como un trabajo extraclase y la exposición de cada grupo puede formar parte del valor porcentual del trabajo cotidiano o evaluarla como un rubro más del trabajo extraclase.

La siguiente lista de cotejo puede ser de utilidad para la evaluación de la técnica y el desarrollo de sus temas. 


\begin{tabular}{|c|c|c|c|c|c|c|}
\hline Rubros & 1 & 2 & 3 & 4 & 5 & Total \\
\hline Presentación del trabajo completo. & & & & & & \\
\hline $\begin{array}{l}\text { Creatividad en la realización de represen- } \\
\text { taciones teatrales. }\end{array}$ & & & & & & \\
\hline $\begin{array}{l}\text { Aportación de materiales e ideas para de- } \\
\text { sarrollar la técnica. }\end{array}$ & & & & & & \\
\hline $\begin{array}{l}\text { Expresión oral (proyección de la voz, } \\
\text { fluidez, buena dicción). }\end{array}$ & & & & & & \\
\hline $\begin{array}{l}\text { Interpretación de una escena de algún } \\
\text { tema, aventura o la forma de hablar de un } \\
\text { personaje. }\end{array}$ & & & & & & \\
\hline $\begin{array}{l}\text { Demuestra por medio de la expresión cor- } \\
\text { poral una escena o aventura de la novela. }\end{array}$ & & & & & & \\
\hline $\begin{array}{l}\text { Interactúa con sus compañeros en las re- } \\
\text { presentaciones. }\end{array}$ & & & & & & \\
\hline Total & & & & & & \\
\hline
\end{tabular}

Estrategia 6: Viajando con Don Quijote en el siglo XXI.

Inteligencias múltiples que incentiva: Lingüística, Intrapersonal e Interpersonal.

Materiales: Hojas, lapiceros.

La estrategia permite a la y el estudiante descubrir el fabuloso mundo de la narración. Incentiva la creatividad literaria, el enriquecimiento de léxico y la expresión escrita. Los temas que se pueden desarrollar con esta técnica pertenecen al objetivo específico \# 5.1 de la Unidad Didáctica. Estos son:
A. Quijotización.
B. Sanchificación.
C. El ideal caballeresco. 
D. El papel de la Iglesia.

E. La sumisión de la mujer.

F. La justicia.

G. Los valores.

El o la estudiante utiliza las aventuras del personaje principal para adaptarlas a su entorno. Por ejemplo, realiza un pequeño cuento donde puede comparar a Ginés de Pasamonte con los asaltantes de ahora que popularmente se les denomina "chapulines".

Esta estrategia también incentiva las inteligencias múltiples conocidas como la intrapersonal y la interpersonal. Ambas le permiten a la y el estudiante plasmar en un escrito o externar por medio de la oratoria, el discurso o poemas sus pensamientos, sentimientos y sueños. Además, la interpersonal le ayuda a integrarse al grupo y participar en diversas actividades.

\section{Pasos}

1. Cada estudiante selecciona una aventura o tema extraído de la obra literaria El Ingenioso Hidalgo Don Quijote de la Mancha.

2. Realiza su creación literaria de forma individual.

3. Posteriormente, se seleccionan algunas aventuras para ser compartidas con el resto del grupo.

\section{Evaluación}

La elaboración de los materiales se asigna como un trabajo extraclase y la exposición de cada grupo puede formar parte del valor porcentual del trabajo cotidiano o evaluarla como un rubro más del trabajo extraclase.

La siguiente lista de cotejo puede ser de utilidad para la evaluación de la técnica y el desarrollo de sus temas. 


\begin{tabular}{|c|c|c|c|c|c|c|}
\hline Rubros & 1 & 2 & 3 & 4 & 5 & Total \\
\hline \multicolumn{7}{|l|}{ Presentación del trabajo completo. } \\
\hline \multicolumn{7}{|l|}{ Creatividad en la elaboración de un cuento. } \\
\hline \multicolumn{7}{|l|}{$\begin{array}{l}\text { Aportación de materiales e ideas para de- } \\
\text { sarrollar la técnica. }\end{array}$} \\
\hline \multicolumn{7}{|l|}{ Desarrollo de la expresión escrita. } \\
\hline \multicolumn{7}{|l|}{$\begin{array}{l}\text { Actitud crítica a la hora de emitir juicios } \\
\text { valorativos. }\end{array}$} \\
\hline \multicolumn{7}{|l|}{$\begin{array}{l}\text { Facilidad en la narración, descripción y } \\
\text { actualización de aventuras con situaciones } \\
\text { cotidianas. }\end{array}$} \\
\hline \multicolumn{7}{|l|}{$\begin{array}{l}\text { Interactúa con sus compañeros en la lec- } \\
\text { tura de sus narraciones. }\end{array}$} \\
\hline Total & & & & & & \\
\hline
\end{tabular}

Propuesta de una unidad didáctica metodológica para el desarrollo en el aula de la novela El Ingenioso Hidalgo Don Quijote de la Mancha

En el estudio de esta novela, tan importante no sólo para el Siglo de Oro de la Literatura Española, sino en la narrativa universal, se deben desarrollar aspectos interesantes de manera que la(el) alumna(o) se sienta motivada(o) para su lectura. Aparte de las estrategias establecidas, se propone de igual manera una Unidad Didáctica, donde la o el docente encuentre el material de apoyo para el desarrollo de la lectura de la novela El Ingenioso Hidalgo Don Quijote de la Mancha, de modo que se mejore el proceso educativo.

Las autoras conciben el concepto Unidad Didáctica como un eje integrador que contiene elementos concatenados en torno de él. Los elementos que integran la unidad son aquellos que componen el currículo: objetivos, contenidos, actividades, técnicas, recursos. 
El planeamiento de unidades cambió la didáctica de la clase, que pasó de las lecciones orientadas por el manual, a las actividades orientadas hacia los problemas o temas que fortalecen el proceso de enseñanza y aprendizaje. También ayuda a cada docente a ver objetivos claros y a seleccionar materiales y actividades variadas. Este procedimiento mejora la calidad de la enseñanza y le brinda al proceso educativo óptimos resultados.

La unidad es una organización de objetivos, actividades y medios, centrada en un propósito o problema y preparada por la o el docente para ser desarrollada en una situación de enseñanza y aprendizaje. No sólo es importante para la o el docente planificar las unidades para comprender y manejar el currículo, sino que la puesta en marcha del plan transforma el aprendizaje en el aula, cambiando todas las técnicas tradicionales y haciendo que la(el) alumna(o) participe realmente en el logro de los objetivos.

También se requiere que tanto la educadora o el educador como la(el) educanda(o) aprovechen los medios audiovisuales y tecnológicos (retroproyector, televisión, videocasete, computadoras, entre otros), que sirvan de herramientas para el desarrollo de los contenidos que se proponen en la Unidad Didáctica.

El uso de la tecnología facilitará el proceso de aprendizaje y beneficiará directamente a la o el estudiante. Los logros que obtendrá esta(e) son:

- Estimulación de la creatividad, el área cognoscitiva, los sentidos, la capacidad de concentración, el área motora fina, la coordinación ojo-mano, las relaciones espaciales y la autoestima.

- Cambio en la percepción del mundo.

- Seguridad y conocimiento para enfrentarse al mundo convulso y competitivo en el cual está inmerso.

\section{Unidad Didáctica}

Niveles: Décimo y Undécimo años.

Eje temático: Análisis literario y crítico de la obra literaria El Ingenioso Hidalgo Don Quijote de la Mancha mediante las inteligencias múltiples.

Tiempo: 60 lecciones. 


\begin{tabular}{|c|c|c|c|c|c|}
\hline $\begin{array}{l}\text { General } \\
\text { 1. Analiza los diver- } \\
\text { sos espacios que } \\
\text { están presentes en } \\
\text { la obra literaria } E l \\
\text { Ingenioso Hidalgo } \\
\text { Don Quijote de la } \\
\text { Mancha. } \\
\text { Específicos } \\
\text { 1.1. Reconoce las rutas } \\
\text { que siguieron Don } \\
\text { Quijote y su escu- } \\
\text { dero, en los paisa- } \\
\text { jes españoles del } \\
\text { siglo XVI. } \\
\text { 1.2. Identificalos valo- } \\
\text { res que resaltan } \\
\text { los protagonistas } \\
\text { de la obra literaria } \\
\text { en estudio. } \\
\text { 1.3. Comprende la crí- } \\
\text { tica que realiza } \\
\text { Miguel de Cer- } \\
\text { vantes al sistema } \\
\text { de la Iglesia. } \\
\text { 1.4. Describe la estruc- } \\
\text { tura social de la } \\
\text { época que reflejan } \\
\text { los personajes. } \\
\text { 1.5. Explica el mundo } \\
\text { interior de los per- } \\
\text { sonajes. }\end{array}$ & $\begin{array}{l}\text { Espacios } \\
\text { 1. Físico } \\
\text { 2. Ético } \\
\text { 3. Social } \\
\text { 4. Sicológico } \\
\text { 5. Religioso } \\
\text { Itinerario de Don Qui- } \\
\text { jote } \\
\text { 1. Tres salidas: } \\
\text { I. Formación del } \\
\text { héroe. } \\
\text { II. Compañía de } \\
\text { Don Quijote. } \\
\text { III. Evolución del } \\
\text { personaje. } \\
\text { 2. Episodios: } \\
\text { I. Itinerantes. } \\
\text { II. Estacionarios. } \\
\text { III. Interpolados. }\end{array}$ & $\begin{array}{l}\text { Para desarrollar los con- } \\
\text { tenidos se puede utilizar } \\
\text { las técnicas Siguiendo la } \\
\text { ruta de Don Quijote y } \\
\text { Cancionero de La Man- } \\
\text { cha. }\end{array}$ & $\begin{array}{l}\text { Materiales para desa- } \\
\text { rrollar la técnica } \\
\text { Cartulina o papel perió- } \\
\text { dico, tijeras, marcado- } \\
\text { res, lápices de colores, } \\
\text { goma, hojas, casete, gra- } \\
\text { badora. } \\
\text { Otros recursos } \\
\text {-Mapa de España del si- } \\
\text { glo XVI. } \\
\text {-Textos de lectura y co- } \\
\text { mentarios para décimo o } \\
\text { undécimo año. } \\
\text {-Español } 10^{\circ} \text { Año. } \\
\text {-Español } 11^{\circ} \text { Año. } \\
\text {-Crestomatía: Español } \\
\text { para bachillerato. } \\
\text {-Otro tipo de literatura } \\
\text { tomada de bibliotecas o } \\
\text { de Internet. }\end{array}$ & $\begin{array}{l}\text { La evaluación de las } \\
\text { técnicas se puede hacer } \\
\text { con las listas de cotejo } \\
\text { que aparecen en la des- } \\
\text { cripción de cada técni- } \\
\text { ca o puede tomarse del } \\
\text { porcentaje del trabajo } \\
\text { extraclase. }\end{array}$ & $\begin{array}{l}\text { Respeto por la diversi- } \\
\text { dad de opiniones. } \\
\text { Creatividadal emitires- } \\
\text { pontáneamente su pro- } \\
\text { ducción. } \\
\text { Actitud positiva ante cl } \\
\text { trabajo cooperativo y la } \\
\text { crítica de los demás. } \\
\text { Autonomía para pensar } \\
\text { y actuar con plena inde- } \\
\text { pendencia. } \\
\text { Apreciación por la lec- } \\
\text { tura. } \\
\text { Responsabilidad en los } \\
\text { trabajos que se le enco- } \\
\text { miendan. } \\
\text { Criticidad al emitir jui- } \\
\text { cios valorativos. }\end{array}$ \\
\hline
\end{tabular}




\begin{tabular}{|c|c|c|c|c|c|}
\hline Objetivos & Contenidos & $\begin{array}{l}\text { Sugerencias } \\
\text { metodológicas }\end{array}$ & Recursos auxiliares & Evaluación & Valores y actitudes \\
\hline $\begin{array}{l}\text { General } \\
\text { 2. Reconoce la varie- } \\
\text { dad temática de la } \\
\text { obra literaria El } \\
\text { Ingenioso Hidal- } \\
\text { go Don Quijote de } \\
\text { la Mancha. } \\
\text { Específicos } \\
\text { 2.1. Distingue el tema } \\
\text { central de la nove- } \\
\text { la. } \\
\text { 2.2. Identifica los te- } \\
\text { mas secundarios } \\
\text { que van íntima- } \\
\text { mente entrelaza- } \\
\text { dos con el tema } \\
\text { principal. } \\
\text { 2.3. Comprende las di- } \\
\text { cotomías que se } \\
\text { presentan en la } \\
\text { novela. } \\
\text { 2.4. Extrae del texto li- } \\
\text { terario elementos } \\
\text { que representan el } \\
\text { humor irónico, } \\
\text { grotesco y cómico } \\
\text { del narrador. }\end{array}$ & $\begin{array}{l}\text { Tema central } \\
\text { El enfrentamiento entre } \\
\text { la realidad y la fantasía } \\
\text { en el ser humano. } \\
\text { Temas secundarios } \\
\text { 1. Justicia. } \\
\text { 2. Amor platónico. } \\
\text { 3. Solidaridad. } \\
\text { 4. Amistad. } \\
\text { 5. Honor. } \\
\text { 6. El ideal caballeres- } \\
\text { co. } \\
\text { 7. La muerte. } \\
\text { 8. La sumisión de la } \\
\text { mujer. } \\
\text { Dicotomías } \\
\text { Ser / parecer } \\
\text { Locura / cordura } \\
\text { Idealismo / realismo } \\
\text { Engaño / desengaño } \\
\text { Estilos del lenguaje } \\
\text { La ironía } \\
\text { Lo cómico } \\
\text { Lo grotesco }\end{array}$ & $\begin{array}{l}\text { Los contenidos se desa- } \\
\text { rrollan por medio de las } \\
\text { técnicas denominadas } \\
\text { El mundo quijotesco en } \\
\text { caricatura y La sátira } \\
\text { de Don Quijote de la } \\
\text { Mancha. }\end{array}$ & $\begin{array}{l}\text { Materiales para desa- } \\
\text { rrollar la técnica } \\
\text { Recurso humano, cartu- } \\
\text { lina, papel periódico u } \\
\text { hojas blancas, lápices de } \\
\text { colores, marcadores. } \\
\text { Otros recursos } \\
\text {-Textos de lectura y co- } \\
\text { mentarios para décimo o } \\
\text { undécimo año. } \\
\text {-Español } 10^{\circ} \text { Año. } \\
\text {-Español } 11^{\circ} \text { Año. } \\
\text {-Crestomatía: Español } \\
\text { para bachillerato. } \\
\text {-Otro tipo de literatura } \\
\text { tomada de bibliotecas o } \\
\text { de Internet. }\end{array}$ & $\begin{array}{l}\text { La evaluación de las } \\
\text { técnicas se puede hacer } \\
\text { con las listas de cotejo } \\
\text { que aparecen en la des- } \\
\text { cripción de cada técni- } \\
\text { ca o puede tomarse del } \\
\text { porcentaje del trabajo } \\
\text { extraclase. }\end{array}$ & $\begin{array}{l}\text { Respeto por la diversi- } \\
\text { dad de opiniones. } \\
\text { Creatividad al emitir } \\
\text { espontáneamente su } \\
\text { producción. } \\
\text { Actitud positiva ante el } \\
\text { trabajo cooperativo y la } \\
\text { crítica de los demás. } \\
\text { Autonomía para pensar } \\
\text { y actuar con plena inde- } \\
\text { pendencia. } \\
\text { Apreciación por la lec- } \\
\text { tura. } \\
\text { Responsabilidad en los } \\
\text { trabajos que se le enco- } \\
\text { miendan. } \\
\text { Criticidad al emitir jui- } \\
\text { cios valorativos. }\end{array}$ \\
\hline
\end{tabular}




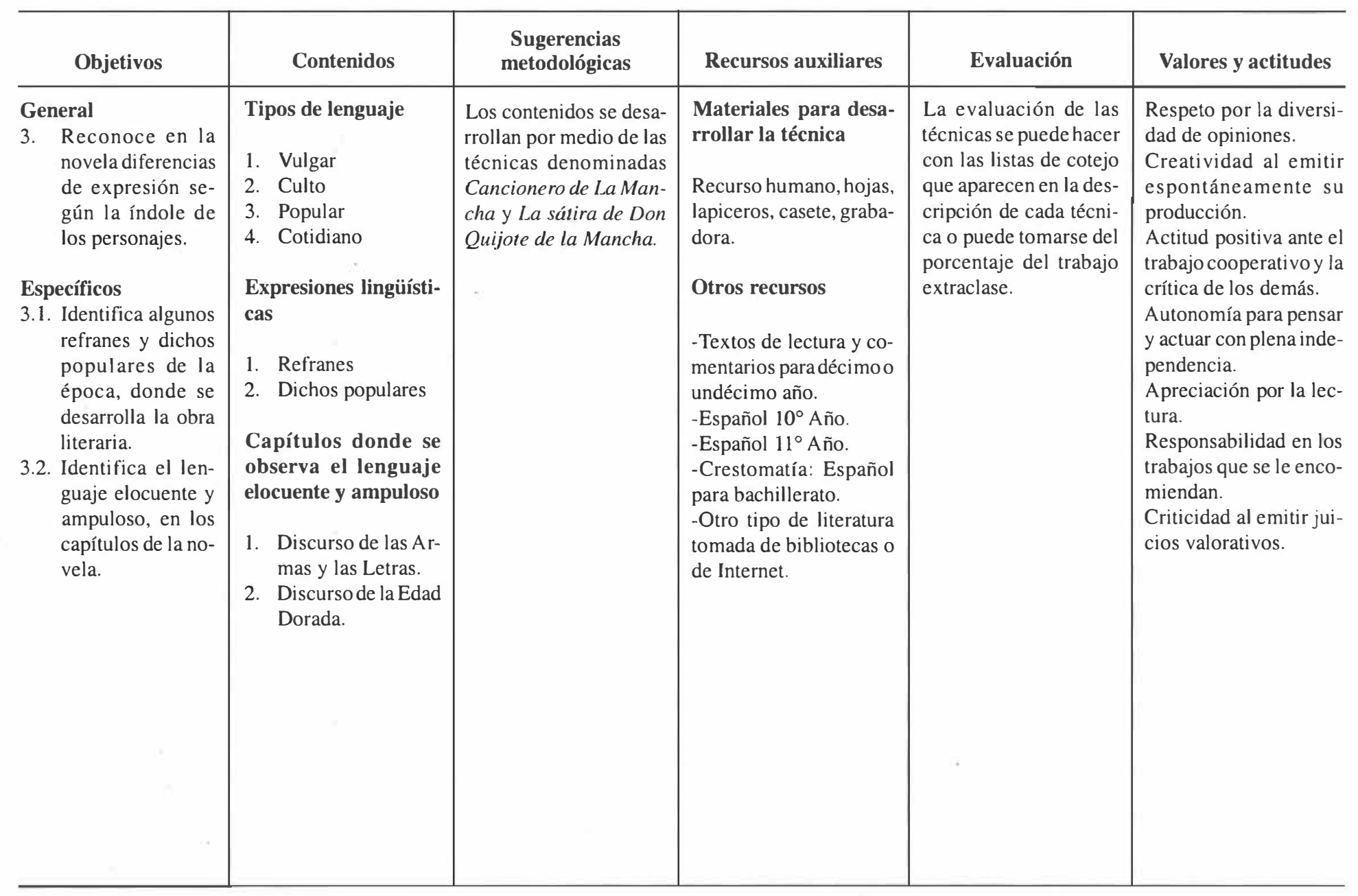




\begin{tabular}{|c|c|c|c|c|c|}
\hline Objetivos & Contenidos & $\begin{array}{l}\text { Sugerencias } \\
\text { metodológicas }\end{array}$ & Recursos auxiliares & Evaluación & Valores y actitudes \\
\hline $\begin{array}{l}\text { General } \\
\text { 4. Identifica elemen- } \\
\text { tos intertextuales e } \\
\text { intratextuales, en } \\
\text { la obra literaria de } \\
\text { Miguel de Cer- } \\
\text { vantes. } \\
\text { Específicos } \\
\text { 4.1. Explica cada una } \\
\text { de las historias } \\
\text { que no correspon- } \\
\text { den a la historia } \\
\text { del personajeprin- } \\
\text { cipal. } \\
\text { 4.2. Distingue la intra- } \\
\text { textualidad que se } \\
\text { da en las relacio- } \\
\text { nes que establecen } \\
\text { los personajes de } \\
\text { algunas historias } \\
\text { con los personajes } \\
\text { de la historia prin- } \\
\text { cipal. }\end{array}$ & $\begin{array}{l}\text { Historias insertadas } \\
\text { (intertextualidad) } \\
\text { Tipos de novela: } \\
\text { 1. Pastoril: Marcela y } \\
\text { Grisóstomo. } \\
\text { 2. Morisca: El cautivo } \\
\text { y la mora. } \\
\text { 3. Sentimental: Car- } \\
\text { denio y Luscinda. } \\
\text { 4. Sicológica: El cu- } \\
\text { rioso impertinente. } \\
\text { 5. Pastoril: Anselmo, } \\
\text { Eugenio y Leandro. } \\
\text { 6. Picaresca: Los Ga- } \\
\text { leotes. } \\
\text { Relación personajes } \\
\text { de historiasinsertadas } \\
\text { con personajes princi- } \\
\text { pales } \\
\text {-Fernando Cura } \\
\text {-Dorotea Barbero } \\
\text {-Cardenio con Sancho } \\
\text {-Luscinda Quijote } \\
\text {-El cautivo } \\
\text {-Zoraida }\end{array}$ & $\begin{array}{l}\text { Los contenidos se desa- } \\
\text { rrollan por medio de las } \\
\text { técnicas denominadas } \\
\text { El ecléctico mundo de } \\
\text { Don Quijote y Sancho } \\
\text { Panza y Cancionero de } \\
\text { La Mancha. }\end{array}$ & $\begin{array}{l}\text { Materiales para desa- } \\
\text { rrollar la técnica } \\
\text { Recurso humano, hojas, } \\
\text { lapiceros, casete, graba- } \\
\text { dora. } \\
\text { Otros recursos } \\
\text {-Textos de lectura y co- } \\
\text { mentarios para décimoo } \\
\text { undécimo año. } \\
\text {-Español } 10^{\circ} \text { Año. } \\
\text {-Español } 11^{\circ} \text { Año. } \\
\text {-Crestomatía: Español } \\
\text { para bachillerato. } \\
\text {-Otro tipo de literatura } \\
\text { tomada de bibliotecas o } \\
\text { de Internet. }\end{array}$ & $\begin{array}{l}\text { La evaluación de las } \\
\text { técnicas se puede hacer } \\
\text { con las listas de cotejo } \\
\text { que aparecen en la des- } \\
\text { cripción de cada técni- } \\
\text { ca o puede tomarse del } \\
\text { porcentaje del trabajo } \\
\text { extraclase. }\end{array}$ & $\begin{array}{l}\text { Respeto por la diversi- } \\
\text { dad de opiniones. } \\
\text { Creatividad al emitir } \\
\text { espontáneamente su } \\
\text { producción. } \\
\text { Actitud positiva ante el } \\
\text { trabajo cooperativo y la } \\
\text { crítica de los demás. } \\
\text { Autonomía para pensar } \\
\text { y actuar con plenainde- } \\
\text { pendencia. } \\
\text { Apreciación por la lec- } \\
\text { tura. } \\
\text { Responsabilidad en los } \\
\text { trabajos que se le enco- } \\
\text { miendan. } \\
\text { Criticidad al emitir jui- } \\
\text { cios valorativos. } \\
\text { Perseverancia, esfuerzo } \\
\text { y constancia en el me- } \\
\text { joramiento de sus es- } \\
\text { critos. } \\
\text { Interés por el arte de } \\
\text { escribir. } \\
\text { Confianza en la capaci- } \\
\text { dad propia para produ- } \\
\text { cir mensajes escritos, } \\
\text { correctos, claros. }\end{array}$ \\
\hline
\end{tabular}




\begin{tabular}{|c|c|c|c|c|c|}
\hline Objetivos & Contenidos & $\begin{array}{l}\text { Sugerencias } \\
\text { metodológicas }\end{array}$ & Recursos auxiliares & Evaluación & Valores y actitudes \\
\hline $\begin{array}{l}\text { General } \\
\text { 5. Actualiza algún } \\
\text { acontecimiento de } \\
\text { la novela con al- } \\
\text { guna situación o } \\
\text { problema social } \\
\text { contemporáneo. } \\
\text { Específico } \\
\text { 5.1. Realiza un breve } \\
\text { cuento, en forma } \\
\text { oral o escrita, para } \\
\text { actualizar la figu- } \\
\text { ra de Don Quijo- } \\
\text { te, su ideal caba- } \\
\text { lleresco y otros } \\
\text { temas más. }\end{array}$ & $\begin{array}{l}\text { Temas } \\
\text { 1. Quijotización. } \\
\text { 2. Sanchificación. } \\
\text { 3. El ideal caballe- } \\
\text { resco. } \\
\text { 4. El papel de la } \\
\text { Iglesia. } \\
\text { 5. La sumisión de la } \\
\text { mujer. } \\
\text { 6. La justicia. } \\
\text { 7. Los valores. }\end{array}$ & $\begin{array}{l}\text { Los contenidos se desa- } \\
\text { rrollan por medio de la } \\
\text { técnica denominada } \\
\text { Viajando con Don Qui- } \\
\text { jote en el siglo XXI. }\end{array}$ & $\begin{array}{l}\text { Materiales para desa- } \\
\text { rrollar la técnica } \\
\text { Hojas, lápices. } \\
\text { Otros recursos } \\
\text {-Textos de lectura y co- } \\
\text { mentarios para décimoo } \\
\text { undécimo año. } \\
\text {-Español } 10^{\circ} \text { Año. } \\
\text {-Español } 11^{\circ} \text { Año. } \\
\text {-Crestomatía: Español } \\
\text { para bachillerato. } \\
\text {-Otro tipo de literatura } \\
\text { tomada de bibliotecas o } \\
\text { de Internet. }\end{array}$ & $\begin{array}{l}\text { La evaluación de las } \\
\text { técnicas se puede hacer } \\
\text { con las listas de cotejo } \\
\text { que aparecen en la des- } \\
\text { cripción de cada técni- } \\
\text { ca o puede tomarse del } \\
\text { porcentaje del trabajo } \\
\text { extraclase. }\end{array}$ & $\begin{array}{l}\text { Respeto por la diversi- } \\
\text { dad de opiniones. } \\
\text { Creatividad al emitir } \\
\text { espontáneamente su } \\
\text { producción. } \\
\text { Actitud positiva ante el } \\
\text { trabajocooperativo y la } \\
\text { crítica de los demás. } \\
\text { Autonomía para pensar } \\
\text { y actuar con plena inde- } \\
\text { pendencia. } \\
\text { Apreciación por la lec- } \\
\text { tura. } \\
\text { Responsabilidad en los } \\
\text { trabajos que se le enco- } \\
\text { miendan. } \\
\text { Criticidad al emitir jui- } \\
\text { cios valorativos. }\end{array}$ \\
\hline
\end{tabular}




\section{Referencias}

Alvarado de Varilly, Jesusita. (1995). El proceso de evaluación de los aprendizajes. San José: Editorial Universidad Estatal a Distancia.

Antunes, Celso. (1998). Estimular las Inteligencias Múltiples. Madrid: Ediciones Narcea, S.A.

Avolio de Cols, Susana. (1970). Planeamiento y evaluación de la tarea escolar. Buenos Aires: Ediciones Troquel.

Barrantes Echavarría, Rodrigo. (1999). Investigación: un camino al conocimiento, un enfoque cualitativo y cuantitativo. San José: Editorial Universidad Estatal a Distancia.

Brenes Espinoza, Fernando. (1987). Evaluación diagnóstica, formativa y sumativa de los aprendizajes. San José: Editorial Universidad Estatal a Distancia.

Coll, César. (1992). Psicología y currículo. España: Ediciones Paidós.

Díaz Artavia, Francisco y otros. (1998). El enfoque de enseñanza-aprendizaje utilizado por los profesores de Estudios Sociales en la Región Educativa de Puriscal. Proyecto de graduación presentado para optar al grado de Licenciatura en Ciencias de la Educación con énfasis en Educación Cívica. UNED.

Gutiérrez, Francisco. (1996). Pedagogía y Pedagogismo. San José: Editorial La Nación.

Hernández, R.; Fernández, G. y Baptista, P. (1997). Metodología de la investigación. México, D.F.: Impresora OFGLOMA.

Lafourcade, Pedro. (1970). Evaluación de los aprendizajes. Buenos Aires: Editorial Kapelusz, S.A.

López, Olimpia. (1996). ¿Educación para el mercado o la vida? San José: Editorial La Nación.

Ministerio de Educación Pública. (1995). Marco de referencia y directrices técnicas para la evaluación en el sistema de evaluación formal. Normas básicas reguladoras del proceso educativo. Consejo Superior de Educación, febrero.

Ministerio de Educación Pública. (1994). División de Desarrollo Curricular: Programa de Mejoramiento de la calidad de la educación. Componente de evaluación. Evaluación de los Aprendizajes. San José, Costa Rica.

Ministerio de Educación Pública. (1994). Política educativa hacia el siglo XXI. Consejo Superior de Educación. Despacho del Ministro. San José.

Ministerio de Educación Pública. (1997). Programa de mejoramiento de la calidad de la educación general básica. Componente de adecuación curricular. Estrategias para evaluar el trabajo cotidiano. Departamento de Evaluación Educativo.

Minsky, Larissa. (2000). Revista Dominical: Mentes Fértiles. Pp. 6-26. San José: Editorial La Nación.

Molina, Zaida. (1997). Planeamiento didáctico: fundamentos, principios, estrategias y procedimientos para su desarrollo. Pp. 108-125. 
Seas Tencio, Jenny. (1997). Guía de estudio. Evaluación de los aprendizajes. San José, Costa Rica: Editorial Universidad Estatal a Distancia.

Sierra, C. (1989). Técnicas de investigación social: teoría y ejercicios. Madrid, España: Editorial Paninfo.

Torres Faúaz, Ana Cecilia. (1995). Artículo: Investigación cualitativa.

Torres Faúaz, Ana Cecilia. (1995). Artículo: Investigación participativa.

Verlee, Linda. Aprender con todo el cerebro. Berkeley: Editorial Martínez Roca. 